Cukurova Üniversitesi Mühendislik Fakültesi Dergisi, 36(4), ss. 1127-1136, Aralık 2021

Cukurova University Journal of the Faculty of Engineering, 36(4), pp. 1127-1136, December 2021

\title{
Denim Kumaşlara Çevre Dostu Ön Terbiyesiz Boyama Metodunun Uygulanması
}

\author{
Serin MEZARCIÖZ ${ }^{* 1}$ ID 0000-0002-0457-1500 \\ Serdal SIRLIBAŞ ${ }^{2}$ ID 0000-0002-0926-6791
}

\author{
${ }^{1}$ Çukurova Üniversitesi, Mühendislik Fakültesi, Tekstil Mühendisliği Bölümü, Adana \\ ${ }^{2}$ Bossa T.A.Ş., Hacı Sabancı Organize Sanayi Bölgesi, Adana
}

Geliş tarihi: 24.06.2021 Kabul tarihi: 10.12.2021

\begin{abstract}
Atıf şekli/ How to cite: MEZARCIÖZ, S., SIRLIBAŞ, S., (2021). Denim Kumaşlara Çevre Dostu Ön Terbiyesiz Boyama Metodunun Uygulanması. Çukurova Üniversitesi, Mühendislik Fakültesi Dergisi, 36(4), 1127-1136.
\end{abstract}

\section{$\ddot{O} z$}

Bu çalışmada, geleneksel sülfür boyamaya alternatif olarak çevreci ve sürdürülebilir bir boyama yöntemi geliştirilmiştir. Bu yeni boyama metodu ile konvansiyonel denim kumaş özellikleri daha az proses ve daha düşük su ve kimyasal kullanımı ile elde edilmeye çalışılmıştır. Hem konvansiyonel yöntem ile hem de yeni yöntem ile boyanan kumaşların renk, elastikiyet, kalıcı uzama ve seçilen bazı haslık değerleri karşılaștırmalı olarak incelenmiştir. Çalışma sonuçlarına göre; spektrofotometrik sonuçlar elde edilen yeni rengin konvansiyonel boyama ile elde edilen renge göre daha açık olduğunu gösterse de kumaşlar görsel olarak birbirlerine oldukça yakın renklerdedir. Yeni metot kumaşların sürtünme haslığını iyileştirmiş, ancak yıkama ve ter haslığı değerlerinde önemli bir değişiklik yaratmamıştır. Uygulanan yeni metodun kumaşların elastikiyet ve kalıcı uzama değerleri üzerinde de önemli bir değişikliğe sebep olmadığı görülmüştür.

Anahtar Kelimeler: Denim, Sürdürülebilirlik, Sülfür boyama

\section{Application of Eco-friendly and Non-pretreatment Dyeing Method to Denim Fabrics}

\begin{abstract}
In this study, an environmentally friendly and sustainable dyeing method has been developed as an alternative to traditional sulfur dyeing. With this new dyeing method, conventional denim fabric properties have been tried to be achieved with less processes and less water and chemical use. Color, elasticity, growth and some selected fastness values of fabrics dyed both with the conventional method and with the new method were examined comparatively. According to the results of the study; although the spectrophotometric results show that the new color obtained is lighter than the color obtained by conventional dyeing, the fabrics are visually very close to each other. The new method improved the rubbing fastness of the fabrics, but did not cause a significant change in the washing and perspiration fastness values. It was observed that the new method applied did not cause any significant changes on the elasticity and growth values of the fabrics.
\end{abstract}

Keywords: Denim, Sustainability, Sulfur dyeing

*Sorumlu yazar (Corresponding author): Serin MEZARCIÖZ, smavruz@cu.edu.tr 


\section{GíRiş}

Denim kumaşlar dayanıklı ve zor aşınan kumaşlar olduğu için ilk denim giysiler, iş giysileri olarak üretilmiş ve kullanılmıştır. Zaman içerisinde yeni kesimler, otantik tasarımlar, boncuklu süslemeler ve işlemeler ile şekillenen denim giysiler, her yerde ve toplumun her kesiminde giyilebilen giysiler haline gelmiştir. Geçen sürede denim kumaş ve denim kumaşlardan yapılan ürünler, insanların yaşam tarzlarının değişmesiyle birlikte değişmiş ve gelişmiştir. Denim kumaş en çok pamuk lifinden üretilen, bunun yanında son yıllarda içeriğinde poliester, elastan, keten ve viskon gibi lifler de kullanılan, klasik tiplerinde atkısı boyasız, çözgüsü indigo boyarmadde ile boyalı, çeşitli gramajlarda dokunabilen ve geniş desen yelpazesine sahip bir dokuma kumaş cinsidir [1]. Geçmişte ekonomiklik ve dayanıklılığı için tercih edilen ve günlük yaşantımızda hafta sonları kullanılabilen denim ürünler, artık günlük hayatın vazgeçilmez bir parçası olmuş, spor kıyafetlerin yanı sıra gece kıyafetlerinde, ayakkabı, terlik ve çanta üretiminde de kullanılmaya başlanmıştır [2].

Denim kumaş üretimi için uygulanan işlemler, iplik üretimi, halat sarma, indigo boyama, halat açma, haşıllama, dokuma, terbiye işlemleri, kalite kontrol ve kumaş sevki gibi kademeleri içermektedir. Denim kumaş üretimi için örnek işlem akış şeması Şekil 1'de verilmiştir [3].

1980'li yıllardan günümüze denim kumaş üretimi; dokuma, boyama ve yıkama aşamalarında sürekli değişik metotlar denenerek çeşitlendirilmiştir. Klasik denim anlayışının dışına çıkılmasıyla, pamuk ile birlikte viskon, polyester, tensel, elastan gibi doğal, yapay ve rejenere lifler de kullanılmaya başlanmış ve her birinin denimde görüntü ve moda anlayışına yön verdikleri adımlar olmuştur. Denim kumaş indigo boyarmadde ile özdeşleşmiş olsa da son yıllarda çözgü ipliği sülfür boyalı olarak dokunmuş ürünlerin toplam denim ürün grubu içindeki payı artmaktadır. Sülfür boyarmaddenin düşük maliyette ve farklı renk paletine sahip olması, tüketicinin taleplerinin bir kısmını sülfür boyalı kumaştan yapılmış ürünlere yönlendirmiştir.

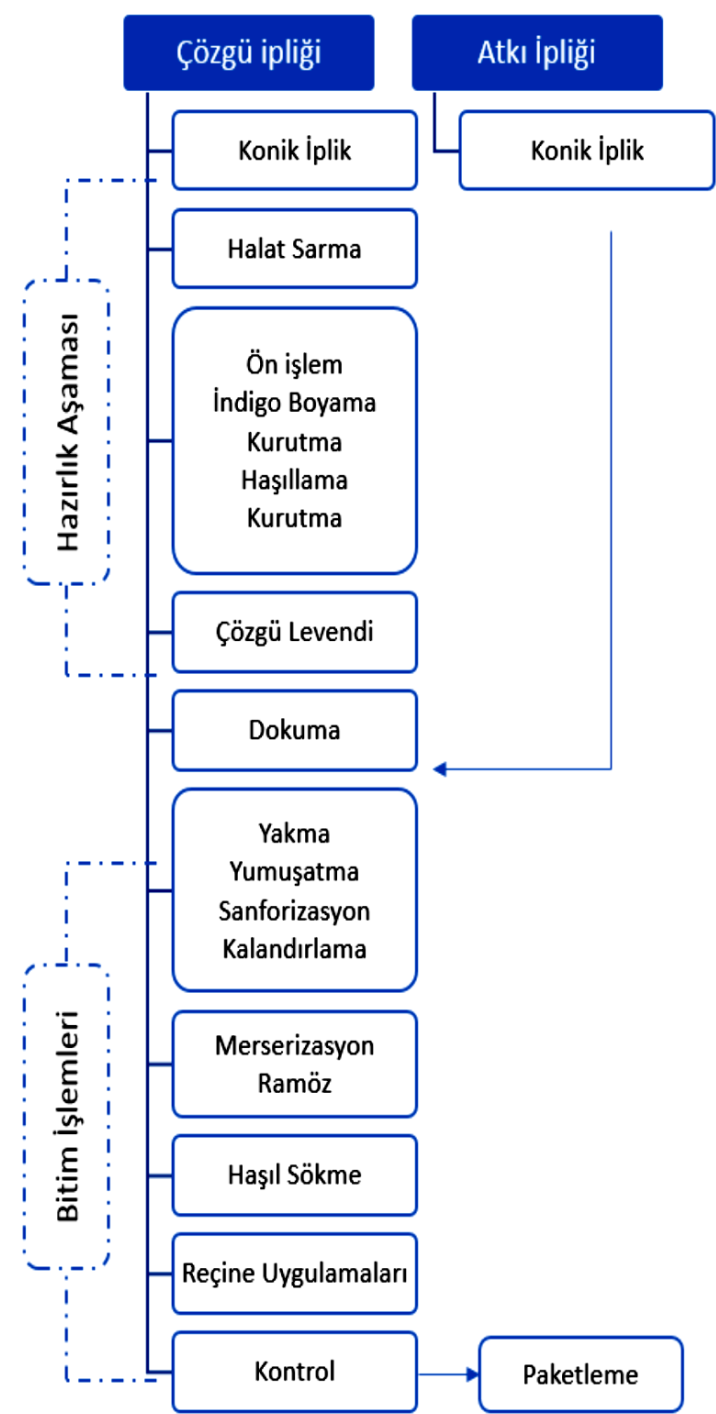

Şekil 1. Denim kumaş üretimi için işlem akışı [3]

Sülfür boyarmadde tanımı, bir yandan üretim yöntemine ancak aynı zamanda da aplikasyon yöntemine atıfta bulunur. Bunlar suda çözünmeyen çok moleküllü bağlardır ve kükürdün bazı organik bağlarla birleşmesinden oluşmuştur. Kükürt sodyumu ( $\mathrm{Na}_{2} \mathrm{~S}-$ Sodyum sülfit) ile redüksiyon sonucunda boyarmadde suda çözünebilir hale getirilir. Suda çözünebilen şeklinin lif ile afinitesi yüksektir. Boyama sonrasında boyarmadde oksitlenme ile suda çözünmeyen haline geri dönüştürülür (Şekil 2) [4]. 
Selüloz elyafin, özellikle pamuğun renklendirilmesinde kullanılmaktadırlar. Elyaf fiksasyonu \%60-70 civarındadır Renkleri parlak olmamakla beraber yaş haslıkları çok yüksek ve fiyatları çok düşüktür [5].

$$
\begin{aligned}
& +\mathrm{Na}_{2} \mathrm{~S}+\mathrm{O}_{2} \\
& \mathrm{~F}-\mathrm{S}-\mathrm{S}-\mathrm{F} \longrightarrow 2 \mathrm{~F}-\mathrm{S}-\mathrm{Na} \longrightarrow \mathrm{F}-\mathrm{S}-\mathrm{S}-\mathrm{F} \\
& \text { Boyarmadde Lökoform, Lifin üzerinde geri oksitlenen } \\
& \text { çözünebilir, life çekilir boyarmadde }
\end{aligned}
$$

Şekil 2. Sülfür boyarmadde ile boyama [4]

Selüloz ve karışımlarından oluşan çözgü ipliğinin kontinü olarak sülfür boyanması, indigo boyamada olduğu gibi daha çok halat boya ve slasher boyama makinelerinde yapılmaktadır. Bu makinelerin yer ihtiyacı ve yatırım maliyeti yüksektir ve her boya terbiye işletmesi bu makineler olmadığı için bu tarz üretim yapamamaktadır. Ayrıca sülfür boyama öncesi etkili bir ön terbiye işlemi de gerekmektedir. Yakma, haşıl sökme, kasar, yıkama, merserizasyon, kurutma, kostikleme, pişirme prosesleri ön terbiyede yapılan işlemler olarak sıralanabilir. İşletmelerin makine parkına, kumaşın daha sonra göreceği işleme, müşteri talebine, elyaf çeşidi ve karışım oranına göre ön terbiyede yapılacak işlemler değişkenlik göstermektedir ancak en azından 2-3 işlem mutlaka yapılmaktadır.

Bu çalışmada, ön terbiye işlemleri yapılmadan çok kısa prosesle modaya uygun spor tarzı, efekt alabilen kumaş üretilmesi sağlanmaya çalışılmıştır.

\section{MATERYAL VE METOT}

\subsection{Materyal}

Çalışmada kullanılacak denim kumaşın çözgüsü \%100 pamuklu Ne 13,5/1 olup, atkı ipliği 97/3 pamuk/elastan $\mathrm{Ne} 16 / 1$ 'dir. İpliklere ve bu ipliklerden üretilen kumaşlara ait özellikler Çizelge 1ve 2'de verilmiştir.

Çizelge 1. İpliklere ait özellikler

\begin{tabular}{|l|c|c|c|c|c|c|c|}
\hline & Rkm & $\begin{array}{c}\text { Kopma } \\
\text { uzaması } \\
(\boldsymbol{\%})\end{array}$ & $\begin{array}{c}\text { Düzgünsüzlük } \\
(\mathbf{\%} \mathbf{U})\end{array}$ & Tüylülük & $\begin{array}{c}\text { Ince yer } \\
(-\mathbf{5 0} \%)\end{array}$ & $\begin{array}{c}\text { Kalın yer } \\
(\mathbf{+ 5 0 \%})\end{array}$ & $\begin{array}{c}\text { Neps } \\
(\mathbf{+ 2 8 0} \%)\end{array}$ \\
\hline Ne 16/1 & 11,9 & 9,21 & 11,6 & 6,93 & 0 & 304 & 37 \\
\hline Ne 13,5/1 & 17,2 & 6,39 & 16,1 & 6,65 & 9 & 225 & 12 \\
\hline
\end{tabular}

Çizelge 2. Üretilen kumaşa ait özellikler

\begin{tabular}{|c|c|c|c|c|c|c|c|}
\hline $\begin{array}{c}\text { Örgü } \\
\text { tipi }\end{array}$ & $\begin{array}{c}\text { Atkı iplik } \\
\text { numarası } \\
\text { (Ne) }\end{array}$ & $\begin{array}{c}\text { Çözgü iplik } \\
\text { numarası (Ne) }\end{array}$ & $\begin{array}{c}\text { Atkı sıklı̆̆ı } \\
(\text { tel/cm) }\end{array}$ & $\begin{array}{c}\text { Çözgü } \\
\text { sıklığı } \\
(\text { tel/cm) }\end{array}$ & $\begin{array}{c}\text { Tarak } \\
\text { numarası }\end{array}$ & $\begin{array}{c}\text { Tarak eni } \\
(\mathbf{c m})\end{array}$ & $\begin{array}{c}\text { Gramaj } \\
\left(\mathbf{g} / \mathbf{m}^{2}\right)\end{array}$ \\
\hline $3 / 1 \mathrm{Z}$ & $13.5 / 1$ & $16 / 1$ & 20.5 & 30 & $135 / 2$ & 215 & 330 \\
\hline
\end{tabular}

\subsection{Metot}

İplik üretimleri gerçekleştirildikten sonra kumaş üretim ve terbiye işlemleri için iki ayrı proses yürütülmüştür. İlk proseste pad batch boyama makinelerinde konvansiyonel kumaş boyaması uygulanmıştır. Kumaş sırasıyla haşıllama, haşıl sökme, ağartma, yıkama ve kurutma gibi detaylı 
ön terbiye işlemlerinden geçirilmiştir. İkinci işlemde ise azaltılmış bir işlem gerçekleştirilmiştir. Çözgü ipliği hazırlandıktan sonra sadece haşıllama yapılmıştır ve sonraki dokuma ve diğer ard işlemler standart yöntemler kullanılarak uygulanmıştır (ön terbiye işlemleri yapılmamıştır) (Çizelge 3).

Çizelge 3. Prosesler

\begin{tabular}{|c|c|c|c|}
\hline \multicolumn{4}{|l|}{ Metod } \\
\hline \multicolumn{2}{|c|}{ Konvansiyonel metod } & \multicolumn{2}{|l|}{ Yeni metod } \\
\hline Proses & Detay & Proses & Detay \\
\hline Haşıllama & Nişasta & Haşıllama & Nişasta \\
\hline Dokuma & Picanol dokuma tezgahı & Dokuma & Picanol dokuma tezgahı \\
\hline Haşıl sökme & $\begin{array}{l}\text { Sodyum hidroksit }(10 \mathrm{~g} / \mathrm{l} \text {, flotte } \\
\text { oranı:1:100) } 100{ }^{\circ} \mathrm{C} \quad 30 \mathrm{dk} \quad 3 \mathrm{kez} \\
\text { yıkama ardından } 60{ }^{\circ} \mathrm{C} \quad 2 \text { saat } \\
\text { kurutma. }\end{array}$ & - & - \\
\hline Ağartma & $\begin{array}{l}\text { Köpük kesici }(0,5 \mathrm{~g} / \mathrm{l}) \\
\text { Hidrojen peroksit }(60 \mathrm{~g} / \mathrm{l}) \\
\text { Sodyum hidroksit }(45 \mathrm{~g} / \mathrm{l}) \\
\text { İyon tutucu }(7 \mathrm{~g} / \mathrm{l}), \text { slatıc1 }(3,5 \mathrm{~g} / \mathrm{l})\end{array}$ & - & - \\
\hline Y1kama & $30 \mathrm{~m} / \mathrm{dk}$ hiz, $95^{\circ} \mathrm{C}$ & - & - \\
\hline Kurutma & \begin{tabular}{|l} 
Tamburlu kontakt kurutma, $110^{\circ} \mathrm{C}$ \\
tambur sicaklığ
\end{tabular} & - & - \\
\hline Yakma & Ön yüz yakma. 70 m/dk, 12 mbar & Yakma & $\begin{array}{l}\text { Ön yüz yakma. } 70 \mathrm{~m} / \mathrm{dk}, 12 \\
\text { mbar }\end{array}$ \\
\hline Boyama + yıkama & $80 \mathrm{~g}$ black boyama + oksidasyon & Boyama+yıkama & $\begin{array}{lll}80 & \mathrm{~g} & \text { black } \\
\text { boyama+oksidasyon } & \\
\end{array}$ \\
\hline Kurutma & $\begin{array}{l}\text { Boyama makinesinde tamburlu } \\
\text { kontakt kurutma } 35 \mathrm{~h} 1 \mathrm{z} .110{ }^{\circ} \mathrm{C} \\
\text { tambur sicaklığ } 1\end{array}$ & Kurutma & \begin{tabular}{lrr} 
Boyama & \multicolumn{2}{c}{ makinesinde } \\
tamburlu & kontakt & kurutma \\
35 hız. & $110^{\circ} \mathrm{C}$ & tambur \\
sicaklığ & &
\end{tabular} \\
\hline Apre/fikse & 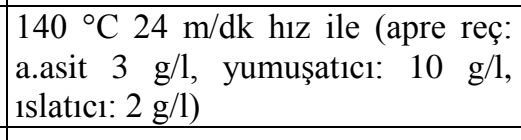 & Apre/fikse & $\begin{array}{l}140{ }^{\circ} \mathrm{C} 24 \mathrm{~m} / \mathrm{dk} \text { hız ile (apre } \\
\text { reç: a.asit } 3 \mathrm{~g} / \mathrm{l} \text {, yumuşatıcı: } \\
10 \mathrm{~g} / \mathrm{l} \text {, 1slatıcı: } 2 \mathrm{~g} / \mathrm{l} \text { ) }\end{array}$ \\
\hline Sanfor & $30 \mathrm{~m} / \mathrm{dk}$ h1z & Sanfor & $30 \mathrm{~m} / \mathrm{dk} \mathrm{h} 1 \mathrm{z}$ \\
\hline
\end{tabular}

Proses tablosu incelendiğinde yeni metotta; haşıl sökme, ağartma, yıkama ve kurutma işlemlerinin yer almadığı görülmektedir. $\mathrm{Bu}$ yeni yöntem ile yenilikçi/sürdürülebilir prosesler ile konvansiyonel boyama ile elde edilen görüntüye ulaşılmaya çalışılmıştır. Böylece işlem daha hızlı, verimli, çevreci hale getirilmiş olacaktır. Çalışma kapsamında kumaşların renk, elastikiyet, kalıcı uzama, yıkama haslığı, ter haslığı ve sürtünme haslığı değerleri incelenmiştir.

Kumaşlara uygulanan testler ve standartları Çizelge 4'de görülmektedir. Tüm numuneler 24 saat standart atmosfer koşullarında kondisyonlandıktan sonra aşağıdaki testler uygulanmıştır. 
Çizelge 4. Kumaşlara uygulanan testler ve standartlar1 [6-10]

\begin{tabular}{|l|l|}
\hline Ölçülen özellikler & İlgili standart \\
\hline Renk ölçümü & - \\
\hline Yıkama haslığı & $\begin{array}{l}\text { TS EN ISO 105 C06: } \\
2001\end{array}$ \\
\hline Sürtünme haslığı & $\begin{array}{l}\text { TS EN ISO 105- } \\
\text { X12:2006 }\end{array}$ \\
\hline Ter haslığ1 & $\begin{array}{l}\text { TS EN ISO 105 } \\
\text { E04:2012 }\end{array}$ \\
\hline pH değeri & TS EN ISO 3071:2009 \\
\hline $\begin{array}{l}\text { Yüzey özelliklerinin } \\
\text { incelenmesi }\end{array}$ & - \\
\hline Elastikiyet & ASTM D3107-07:2015. \\
\hline Kalıcı uzama & ASTM D3107-07:2015. \\
\hline
\end{tabular}

\section{ARAŞTIRMA BULGULARI}

\subsection{Renk Ölçümü}

Yıkama işlemlerindeki gelişmeler ve kullanılan kimyasalların özellikleri arttıkça, denim kumaşlarda değişik yıkama çeşitleri elde edilmiştir. Yıkama işlemi, dikilmiş denim giysisine, özel yıkama makinelerinde belirli reçete ve tekniklere göre yıkama yapılarak değişik renk ve tuşe kazandırılması işlemidir.

Denim kumaştan üretilen ürünler genel olarak endüstriyel yıkama yapılarak satışa sunulmaktadır. $\mathrm{Bu}$ çalışmada uygulanan yeni metodun kumaşın renk değerlerine etkisi incelenirken özellikle bazı endüstriyel yıkamalar sonrası bu değerlerin ölçülmesi ve karşılaştırılmasının daha uygun olduğu düşünülmüştür. $\mathrm{Bu}$ nedenle hem konvansiyonel olarak boyanan kumaşa hem de yeni uygulanan boyama metodu sonucu elde edilen kumaşa endüstriyel yıkamalar yapılmıştır. Böylece yıkamalar sonucu ulaşılabilecek renk tonları da görülmüş, kıyaslamalı analizleri yapılmıştır. Endüstriyel yıkamalar kumaşlara paça formatında uygulanmış olup, reçetesi aşağıda verilmiştir (Çizelge 5).

Çizelge 5. Yıkama reçetesi

\begin{tabular}{|c|c|c|c|c|c|}
\hline & \multirow[b]{2}{*}{ Proses } & \multicolumn{4}{|c|}{ Proses adımları } \\
\hline & & $\begin{array}{l}\text { Süre } \\
(\mathbf{d k})\end{array}$ & $\begin{array}{c}\text { Sicaklık } \\
\left({ }^{\circ} \mathrm{C}\right)\end{array}$ & Kimyasal adı & Miktar \\
\hline \multirow{3}{*}{$\begin{array}{l}\text { Rins } \\
\text { ylkama }\end{array}$} & \multirow{2}{*}{ Yumuşatma } & \multirow{2}{*}{2} & \multirow{2}{*}{30} & Noniyonik yumuşatıcı & $3 \mathrm{ml} / 1$ \\
\hline & & & & Semi-mikro silikon emülsiyonu & $3 \mathrm{ml} / \mathrm{l}$ \\
\hline & Kurutma & 45 & 80 & & \\
\hline \multirow{5}{*}{$\begin{array}{l}\text { Taş } \\
\text { yıkama }\end{array}$} & \multirow{2}{*}{ Taş yıkama } & \multirow{2}{*}{30} & \multirow{2}{*}{45} & Nötr Selülaz- taş enzimi & $3 \mathrm{ml} / \mathrm{l}$ \\
\hline & & & & Polimer bazlı dispergator & $2 \mathrm{ml} / \mathrm{l}$ \\
\hline & \multirow{2}{*}{ Yumuşatma } & \multirow{2}{*}{10} & \multirow{2}{*}{40} & katyonik yumuşatıcı & $3 \mathrm{ml} / \mathrm{l}$ \\
\hline & & & & Semi-mikro silikon emülsiyonu & $3 \mathrm{ml} / 1$ \\
\hline & Kurutma & 45 & 80 & & \\
\hline
\end{tabular}

Kumaşlar rins ve taş yıkama proseslerinden geçirildikten sonra renk değerleri ölçülmüştür. Çünkü yeni metodun özellikle kumaşın renk değerlerinde değişiklik yaratmaması istenmektedir.

Farklı yıkama reçeteleriyle yıkanmış konvansiyonel ve yeni metot numune kumaşlarının
CIELab (L*, a*, b*, $\mathrm{c}^{*}$ ve $\mathrm{h}$ ) değerleri ile $\Delta \mathrm{E}$ renk farklılığı değerleri ölçülmüş ve kıyaslanmıştır (Çizelge 6-7). Çizelge 7 için; referans olarak konvansiyonel metotla boyanmış kumaş renk değerleri esas alınmıştır. Numunelerin yıkama öncesi de renk analizleri yapılmıştır. 
Çizelge 6. Ölçülen CIELab değerleri

\begin{tabular}{|l|l|c|c|c|c|c|}
\hline \multirow{2}{*}{ Numune } & \multirow{2}{*}{ Proses } & \multicolumn{5}{|c|}{ Renk değerleri } \\
\cline { 3 - 7 } & & $\mathbf{L}^{*}$ & $\mathbf{C}$ & $\mathbf{a}^{*}$ & $\mathbf{b}^{*}$ & $\mathbf{h}$ \\
\hline \multirow{3}{*}{$\begin{array}{l}\text { Konvansiyonel metot } \\
\text { ile boyanan kumaş }\end{array}$} & Yıkanmamış & 16,81 & 1,44 & 1,23 & 0,74 & 31,06 \\
\cline { 2 - 7 } & Rins yıkama & 15,87 & 1,28 & 1,16 & 0,54 & 24,88 \\
\cline { 2 - 7 } & Taş yıkama & 15.79 & 0.92 & 0.71 & -0.58 & 321.04 \\
\hline \multirow{2}{*}{$\begin{array}{l}\text { Yeni metot ile } \\
\text { boyanan kumaş }\end{array}$} & Yıkanmamış & 18,31 & 1,12 & 1,02 & $-0,46$ & 336,06 \\
\cline { 2 - 7 } & Rins yıkama & 17,61 & 1,15 & 0,83 & $-0,8$ & 316,18 \\
\cline { 2 - 7 } & Taş yıkama & 22,05 & 2,16 & 0,18 & $-2,15$ & 274,68 \\
\hline
\end{tabular}

Çizelge 7. Yeni metot ile boyanan kumaşların renk farklılı̆̆

\begin{tabular}{|c|c|c|c|c|c|c|c|}
\hline & \multicolumn{6}{|c|}{ Renk farklılığ } & \multirow{2}{*}{ Değerlendirme } \\
\hline & $\Delta \mathbf{L}^{*}$ & $\Delta a^{*}$ & $\Delta \mathbf{b}^{*}$ & $\Delta \mathrm{C}^{*}$ & $\Delta \mathbf{h}^{*}$ & $\Delta \mathbf{E}$ & \\
\hline Yıka & 1,497 & $-0,206$ & $-1,196$ & $-0,316$ & 1,172 & 1,93 & $\begin{array}{l}\text { KALIR (numune daha açık, daha yeşil, } \\
\text { daha mavi, daha zayıf) }\end{array}$ \\
\hline Rins y & 1,739 & $-0,334$ & $-1,337$ & $-0,132$ & 1,372 & 2,22 & $\begin{array}{l}\text { KALIR (numune daha açık, daha yeşil, } \\
\text { daha mavi, daha zayıf) }\end{array}$ \\
\hline Taş yıkama & 6,256 & $-0,537$ & $-1,576$ & 1,243 & 1,108 & 6,47 & $\begin{array}{l}\text { KALIR (numune daha açık, daha yeşil, } \\
\text { daha mavi, daha kuvvetli) }\end{array}$ \\
\hline
\end{tabular}

Spektrofotometrik sonuçlar incelendiğinde elde edilen yeni rengin konvansiyonel boyama ile elde edilen renge göre daha açı olduğu tespit edilmiştir.

Yeni üründe ön işlem olarak haşıl sökme, ağartma, yıkama vb. işlemler bulunmamaktadır. Özellikle haşıl sökme işleminin yapılmamasından dolayı, boyama sırasında boyarmaddeler kumaş içerisine tam olarak nüfuz edememekte ve yüzeyde kalmaktadır. Standart kumaşta ise detaylı ön işlem yapıldığ 1 için liflerin şişmesi ile kumaşın hidrofilitesi artmaktadır. Dolayısıyla boyarmadde daha fazla kumaş içerisine nüfuz etmektedir. Böylelikle konfeksiyon sonrası istenilen renk açıklığı daha kısa işlem süresi ile elde edilmiştir. Detaylı ön terbiye işlemi görmüş kumaşlarda istenilen denim efektinin alınması zordur.

Rins yıkama, klasik bir denim yıkama prosesinde kurutma öncesi yapılan son işlem adımıdır. Yumuşatma ile ürün üzerinde istenen tuşe efektinin verilmesi sağlanır. Kullanılan yumuşatıcı maddeler, kumaşın belirli bir yumuşaklık ve dökümlülüğe sahip olmasını sağlar [11]. Ürün üzerinde istenen eskimiş veya yıpranma efektleri en çok taş yıkama ile gerçekleşmektedir. Buradaki efektler, ürünlerin makineye ve kendi aralarındaki sürtünmelerinden oluşabileceği gibi, bunlar için yardımcı kimyasal olacak selülaz enzimleriyle de sağlanabilmektedir. Ayrıca işletmelerde mekanik sürtünme etkisini artırmak amacıyla ponza taşı da kullanılmaktadır [11,12]. Taş yıkama uygulamasının boyarmadde pigmentlerini uzaklaştırarak kumaşın rengini soldurduğu tespit edilmiştir. Çünkü taş yıkama uygulamalarında kumaş/iplik yıprandıkça kumaş üzerindeki boyarmaddeler akmaktadır. Yeni metot ile boyanan kumaşlarda boyarmadde kumaşa tam nüfuz etmediği için, solma daha fazla olmuştur.

Yıkanmamış kumaşlarda renk farkı daha küçüktür. Aynı yıkamalara tabi tutulmuş standart kumaş ve yeni metot ile boyanan kumaşlarda konvansiyonel kumaş daha koyu kalmakta, üzerindeki sülfür boyayı daha geç atmaktadır. Yıkama yapıldıkça kumaş içerisindeki haşıl bir miktar uzaklaşıp renk açılmaktadır. Detaylı ön terbiye görmüş kumaş rengini koruma eğilimindeyken, yeni metot ile boyanan kumaşın rengi daha kolay açılmıştır. 
Kumaşlara yıkama işlemleri uygulandıktan sonra standart boyanan ve yeni metot ile boyanan kumaşların renk değerleri birbirlerinden uzaklaşmıştır. Çizelge 6 ve 7 incelendiğinde en fazla renk değişiminin taş yıkama uygulamasında olduğu görülmektedir. Ayrıca Şekil 3'de verilen kumaş görüntülerine göre; yeni metot ile boyanan kumaşların renkleri konvansiyonel metot ile boyanan kumaşların rengine oldukça yakındır.
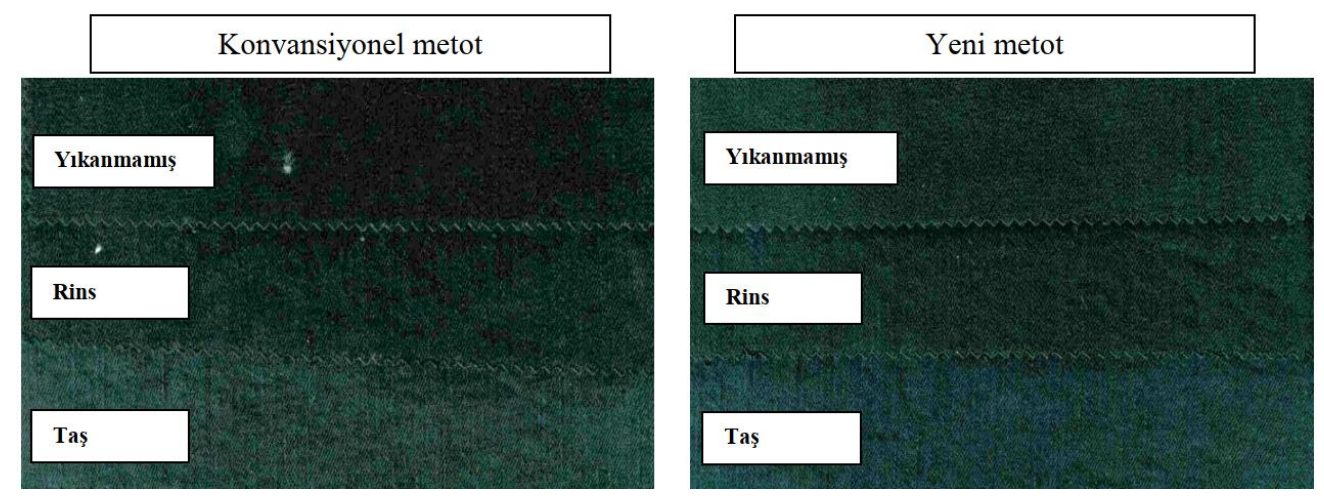

Şekil 3. Kumaş görüntüleri

\subsection{Haslık Testleri}

Denimin yaş sürtünme haslıklarının çok düşük olduğu bilinmektedir. Çizelge 8'e göre yeni metot, kumaşların kuru sürtünme haslığı değerini çok azda olsa iyileştirmiştir. Çünkü yeni metot ile kumaşa nüfuz eden toplam sülfür boyarmadde miktarı daha azdır.

Çizelge 8. Numunelerin sürtünme haslığı ve $\mathrm{pH}$ değerleri

\begin{tabular}{|l|c|c|c|c|}
\hline \multirow{2}{*}{ Test adı } & \multicolumn{2}{|c|}{$\begin{array}{c}\text { Konvansiyonel } \\
\text { metot }\end{array}$} & \multicolumn{2}{c|}{ Yeni metot } \\
\hline $\begin{array}{l}\text { Sürtünmeye } \\
\text { karşı renk } \\
\text { haslığı }\end{array}$ & Kuru & Yaş & Kuru & Yaş \\
\cline { 2 - 5 } & $3 / 4$ & $1 / 2$ & 4 & $1 / 2$ \\
\hline pH & \multicolumn{2}{|c|}{4,2} & \multicolumn{2}{c|}{5,4} \\
\hline
\end{tabular}

Çizelge 9. Diğer haslık değerleri

\begin{tabular}{|c|c|c|c|c|c|c|c|c|c|c|c|c|c|c|}
\hline \multirow[b]{2}{*}{ Test adı } & \multicolumn{7}{|c|}{ Konvansiyonel metot } & \multicolumn{7}{|c|}{ Yeni metot } \\
\hline & Yün & Akrilik & PES & Nylon & Pamuk & Asetat & $\begin{array}{c}\text { Renk } \\
\text { solması }\end{array}$ & Yün & Akrilik & PES & Nylon & Pamuk & Asetat & $\begin{array}{c}\text { Renk } \\
\text { solmas }\end{array}$ \\
\hline $\begin{array}{l}\text { Y1kama } \\
\text { haslığ } 1\end{array}$ & $4 / 5$ & $4 / 5$ & $4 / 5$ & $4 / 5$ & $4 / 5$ & $4 / 5$ & $4 / 5$ & $4 / 5$ & $4 / 5$ & $4 / 5$ & $4 / 5$ & $4 / 5$ & $4 / 5$ & $4 / 5$ \\
\hline $\begin{array}{l}\text { Asidik ter } \\
\text { haslığ }\end{array}$ & $4 / 5$ & $4 / 5$ & $4 / 5$ & $4 / 5$ & $4 / 5$ & $4 / 5$ & $4 / 5$ & $4 / 5$ & $4 / 5$ & $4 / 5$ & $4 / 5$ & $4 / 5$ & $4 / 5$ & $4 / 5$ \\
\hline $\begin{array}{l}\text { Bazik ter } \\
\text { haslığ }\end{array}$ & $4 / 5$ & $4 / 5$ & $4 / 5$ & $4 / 5$ & $4 / 5$ & $4 / 5$ & $4 / 5$ & $4 / 5$ & $4 / 5$ & $4 / 5$ & $4 / 5$ & $4 / 5$ & $4 / 5$ & $4 / 5$ \\
\hline
\end{tabular}

pH değeri yüksek olan kumaşlar, kolaylıkla cilde zarar vererek alerjik reaksiyonlara yol açabilmektedir. Üretim aşamalarında kullanılan her kimyasalın, bitmiş üründeki $\mathrm{pH}$ değerine etkisi bulunmaktadır. pH değeri, yıkama ve nötrleştirme basamaklarında kontrol altına alınabilmektedir [13]. Eko-Teks 100 standardına göre pH tayini ISO 3071 (Potasyum klorür çözeltisi) uyarınca tespit edilmektedir. $\mathrm{Bu}$ standart kapsamında $\mathrm{pH}$ değerinin alt ve üst limit değeri sırasıyla 4,0 ve 7,5 olarak kabul edilmiştir Yeni yöntemle boyanan kumaşın $\mathrm{pH}$ değerinin konvansiyonel yöntemle boyanan kumaşa göre daha alkali olduğu tespit edilmiştir. $\mathrm{Bu} \quad \mathrm{pH}$ değeri, OEKO-TEX standartlarında belirtilen sınırlar içindedir.

Numunelerin diğer haslık değerleri Çizelge 9'da görülmektedir. 
İncelenen yıkama ve ter haslığı değerleri için yeni metot ile boyanan kumaşlar ile konvansiyonel metot ile boyanan kumaşlar arasında refakat bezine akma ve numunenin solma değerleri açısından fark çıkmamıştır. Sonuç olarak; yeni metotta işlem sayısının az olmasının denim kumaşların kullanım esnasında karşılaşacakları yıkama haslığı, asidik ve bazik ter haslığı için olumsuz bir durum yaratmayacağı görülmüştür.

\subsection{Elastikiyet ve Kalıcı Uzama Testi}

Elastikiyet; belirli bir kuvvet altındaki kumaşın gösterdiği kalıcı olmayan uzama eğilimidir. Kalıcı uzama ise belirli kuvvet altında kalan kumaşın yapısında oluşan deformasyonlar sonucunda ilk haline dönememesidir [14]. Numunelere uygulanan elastikiyet ve kalıcı uzama test sonuçları Şekil 4'de verilmiştir.

Test sonuçlarına göre; uygulanan yeni metodun kumaşların elastikiyet ve kalıcı uzama değerleri üzerinde önemli bir değişikliğe sebep olmadığı görülmüştür. $\mathrm{Bu}$ değerler daha çok elastan özelliklerine bağlı olduğundan prosesler sonucunda elastanın herhangi bir zarar görmediği düşünülmektedir. Ayrıca elastan lifi sadece atkı ipliğinde kullanılmış olup, kullanılan haşıl maddesi de sadece çözgü ipliklerine uygulandığından, kumaşların elastikiyet ve kalıcı uzama değerlerinde önemli bir değişiklik görülmemiştir.

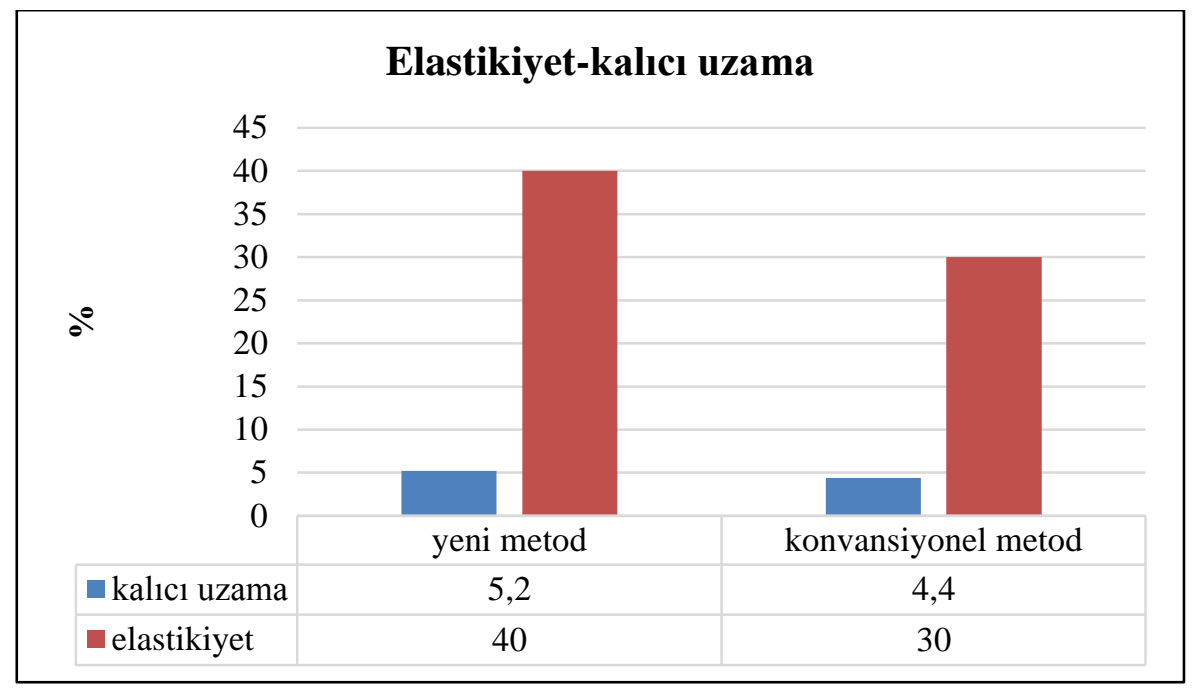

Şekil 4. Elastikiyet ve kalıcı uzama test sonuçları

Çevre dostu bir proses önerilen bu çalışmada, konvansiyonel boyama ve önerilen yeni boyama proseslerinin sahip oldukları ortalama enerji ve su tüketimleri ve bunların çevre üzerindeki etkileri
Çizelge 10'da verilmiştir. Böylelikle somut veriler üzerinden de elde edilen kazanımlar görülebilmektedir.

Çizelge 10. Proseslerin enerji ve bazı çevresel etkileri

\begin{tabular}{|l|c|c|c||c|c|c|c|c|}
\hline & $\begin{array}{c}\mathrm{Su} \\
(1 / \mathrm{m})\end{array}$ & $\begin{array}{c}\text { Elektrik } \\
(\mathrm{kWh} / \mathrm{m})\end{array}$ & $\begin{array}{c}\text { Doğal } \\
\text { gaz } \\
\left(\mathrm{Sm}^{3} / \mathrm{m}\right)\end{array}$ & $\begin{array}{c}\text { Küresel } \\
\text { 1sinma } \\
(\mathrm{GWP100a}) \\
\left(\mathrm{kg} \mathrm{CO} \mathrm{eq}^{2}\right.\end{array}$ & $\begin{array}{c}\text { Ozon tabakas1 } \\
\text { incelmesi (kg } \\
\text { CFC-11 eq) }\end{array}$ & $\begin{array}{c}\text { İnsan } \\
\text { toksitisesi } \\
(\mathrm{kg} 1,4-\mathrm{DB} \text { eq) }\end{array}$ & $\begin{array}{c}\text { Asidifikasyon } \\
\left(\mathrm{kg} \mathrm{SO}_{2} \text { eq }\right)\end{array}$ & $\begin{array}{c}\text { Ottrofikasyon } \\
\left(\mathrm{kg} \mathrm{PO}_{4}--- \text { eq }\right)\end{array}$ \\
\hline Konvansiyonel metot & 74,85 & 0,41 & 0,44 & 0,771407751 & 0,000000086 & 0,123296338 & 0,002202501 & 0,000949554 \\
\hline Yeni metot & 30,9 & 0,27 & 0,25 & 0,461361803 & 0,000000050 & 0,075727547 & 0,001363031 & 0,000598619 \\
\hline Fark & 43,95 & 0,14 & 0,19 & 0,310045948 & 0,000000037 & 0,047568791 & 0,000839470 & 0,000350935 \\
\hline
\end{tabular}


Çizelge 10'a göre yeni metot ile işlem görmüş kumaşların prosesinde kullanılan su, enerji ve doğalgaz tüketimi çok düşüktür. Ayrıca azaltılmış proses kullanıldığında çevre üzerindeki olumsuz etki de önemli ölçüde azalmaktadır. Dolayısıyla çalışmamızda önerilen yeni boyama metodunun çevre dostu ve sürdürülebilir olduğu görülmektedir.

\section{SONUÇLAR}

Çalışma sonuçlarına göre; çözgü ipliği sadece haşıllanmış, dokunmuş, yaş ön terbiye işlemi yapılmadan boyanıp mamül hale getirilen kumaş endüstriyel yıkama işlemlerine tabi tutulduktan sonra, detaylı ön terbiye görmüş ve sonrasında tekrar boyanmış kumaş görüntüsüne benzemektedir. Böylece halat boyama makineleri olmadan, su, enerji, zaman, işçilik ve kimyasal tasarrufu sağlanarak birçok boya terbiye işletmesinin kolaylıkla yapabileceği denim kumaş üretiminin gerçekleştirilebileceği görülmüştür.

Kumaşlara yıkama işlemleri uygulandıktan sonra konvansiyonel boyanan ve yeni metot ile boyanan kumaşların renk değerleri birbirlerinden uzaklaşmıştır. Uygulanan yeni metodun kumaşların elastikiyet ve kalıcı uzama değerleri üzerinde önemli bir değişikliğe sebep olmadığı tespit edilmiştir.

Yeni metot ile boyanmış kumaşların kuru sürtünme haslığı değerleri iyileşmiş, $\mathrm{pH}$ ve diğer haslık değerlerinde önemli değişiklikler olmamıştır.

Çevre kirliliğinde tekstil sektörünün oynadığı büyük rol, doğal hayatın korunabilmesi, kaynakların sürdürülebilir olması, çevre hukuku ile ilgili gelişmeler ve rakiplerin çoğalması işletmelere birçok sorumluluk yüklemiştir. Bunlardan biri ve en önemlisi daha az su, kimyasal, boya, enerji ve zaman kullanarak çevreye sayg1l1, amaca uygun ve ucuz ürün üretmektir. $\mathrm{Bu}$ amaçla çevre dostu bir proses önerilen bu çalışmada, konvansiyonel boyama ve önerilen yeni boyama proseslerinin sahip oldukları çevresel yükler de incelendiğinde oldukça iyi kazanımlar elde edildiği söylenebilmektedir.

$\mathrm{Bu}$ yeni yöntem ile yenilikçi/sürdürülebilir prosesler elde edilmeye ve konvansiyonel boyama ile elde edilen görüntü ve fiziksel özelliklere ulaşılmaya çalışılmıştır.

\section{TEŞEKKÜR}

$\mathrm{Bu}$ çalışma TÜBİTAK (TEYDEB) tarafindan desteklenmiştir. Proje numarası: 3190159

\section{KAYNAKLAR}

1. Seyrek Kurban, N., Babaarslan, O., 2019. Süper Streç Denim Kumaşların Özelliklerine Dair Literatür İncelenmesi, Tekstil ve Mühendis, 26(113), 104-115.

2. Bağıran, İ.C., 2011. Denim Y1kamada Karşılaşılan Sorunlar ve Bunlara Yönelik Çözüm Önerileri. Yüksek Lisans Tezi, Ege Üniversitesi, Fen Bilimleri Enstitüsü Tekstil Mühendisliği, Anabilim Dalı, İzmir, 293.

3. Üstüntağ, S., 2018. Denim Kumaşlara Uygulanan Kaplama Proseslerinin Taguchi Metodu ile İncelenmesi. Doktora Tezi, Erciyes Üniversitesi, Fen Bilimleri Enstitüsü, Tekstil Mühendisliği Anabilim Dalı, Kayseri, 135.

4. Kıroğlu, M., 2018. Levent Boyama Kalitesinin İyileştirilmesi Yöntemleri. Yüksek Lisans Tezi, Bartın Üniversitesi, Fen Bilimleri Enstitüsü, Tekstil Mühendisliği Anabilim Dalı, Bartın, 63.

5. Başer, İ., İnanıc1, Y., 1990. Boyarmadde Kimyas1. Marmara Üniversitesi, Teknik Eğitim Fakültesi, Tekstil Eğitimi Bölümü Yayınları, İstanbul, 216.

6. TS EN ISO 105 C06: 2001. Tekstil-Renk Haslığ1 Deneyleri-Bölüm C06: Evsel ve Ticarî Yıkamaya Karşı Renk Haslığı.

7. TS EN ISO 105-X12, 2016. Tekstil-Renk Haslığ1 Deneyleri-Bölüm X12: Sürtmeye Karş1 Renk Haslığı Tayini.

8. TS EN ISO 105-E04, 2006. Tekstil-Renk Haslığ Deneyleri-Bölüm e04: Terlemeye Karş1 Renk Haslığı Tayini.

9. TS EN ISO 3071, 2009. Tekstil-Sulu Özütte ph Tayini. 
10. ASTM D3107-07:2015. Standard test Methods for Stretch Properties of Fabrics Woven from Stretch Yarns.

11. Çetiner, S., 2006. Seçilmiş Denim Kumaş ve Dikiş İpliklerinde Yıkama İşleminin Dikiş Performansı Üzerindeki Etkisi. Yüksek Lisans Tezi, Kahramanmaraş Sütçü İmam Üniversitesi, Fen Bilimleri Enstitüsü, Tekstil Mühendisliği Anabilim Dalı, Kahramanmaraş, 48.

12. Toksöz, M., Mezarciöz, S., 2013. Denim Kumaşlara Uygulanan Özel Yıkama Uygulamaları. Çukurova Üniversitesi Mühendislik Mimarlık Fakültesi Dergisi, 28(2), 141-147.

13. Bahadir Unal, Z., Sekeroglu., S., 2017. Research of Required Qualifications for Baby Clothes from Past to Present, Aksaray J. Sci. Eng. 1(2), 71-85.

14. Baykuş D., Oğulata, R.T. 2019. Denim Kumaşlarda Özlü İplik Kullanımının Elastikiyet ve Kalıcı Uzama Özelliklerine Etkisi, Tekstil ve Mühendis, 26 (116), 372-380. 